\title{
Prevalence and Safety of Off-Label Use of Chemotherapeutic Agents in Older Patients With Breast Cancer: Estimates From SEER-Medicare Data
}

\author{
Anne A. Eaton, MS; Camelia S. Sima, MD, MS; and Katherine S. Panageas, DrPH
}

\begin{abstract}
Background: Prescribing drugs outside of the label indication is legal and may reflect standard practice; however, some off-label use may be inappropriate. This study measured the prevalence and safety of off-label use both in accordance with practice guidelines and inconsistent with practice guidelines in older patients with breast cancer. Patients and Methods: The SEER-Medicare data set was used to identify women diagnosed with breast cancer. Intravenous chemotherapy was identified using Medicare claims and classified as either on-label, off-label but included in the NCCN Clinical Practice Guidelines in Oncology (NCCN Guidelines) for Breast Cancer ("off-label/supported"), or off-label and not included in the NCCN Guidelines ("off-label/unsupported"). Hospitalization/emergency department (ED) admission rates were compared. Results: A total of 13,347 women were treated with 16,127 regimens (12\% of women switched regimen); $64 \%$ of regimens were offlabel/supported, $25 \%$ were on-label, and $11 \%$ were off-label/unsupported, and hospitalization/ED admission occurred in $27 \%$, 25\%, and $32 \%$ of regimens, respectively $(\mathrm{P}<.0001)$. Drugs never included in the NCCN Guidelines for Breast Cancer accounted for $19 \%$ of off-label/unsupported use ( $1 \%$ of total use). Conclusions: Off-label use without scientific support was not common, whereas $64 \%$ of use was off-label/ supported, reflecting the fact that widely accepted indications are often not tested in registration trials. Off-label/supported use will likely increase as more drugs are expected to have activity across cancer sites, and therefore understanding the implications of such use is critical. J Natl Compr Canc Netw 2016;14(1):57-65
\end{abstract}

\section{NCCN: Continuing Education}

\section{Accreditation Statement}

This activity has been designed to meet the educational needs of physicians and nurses involved in the management of patients with cancer. There is no fee for this article. No commercial support was received for this article. The National Comprehensive Cancer Network (NCCN) is accredited by the ACCME to provide continuing medical education for physicians.

NCCN designates this journal-based CME activity for a maximum of 1.0 AMA PRA Category 1 Credit $^{\mathrm{TM}}$. Physicians should claim only the credit commensurate with the extent of their participation in the activity.

NCCN is accredited as a provider of continuing nursing education by the American Nurses Credentialing Center's Commission on Accreditation.

NCCN designates the education activity for a maximum of 1.0 contact hour. Accreditation as a provider refers to recognition of educational activities only; accredited status does not imply

From the Department of Epidemiology and Biostatistics, Memorial Sloan Kettering Cancer Center, New York, New York.

Submitted May 29, 2015; accepted for publication November 6, 2015.

Ms. Eaton and Dr. Panageas have disclosed that they have no financial interests, arrangements, affiliations, or commercial interests with the manufacturers of any products discussed in this article or their competitors. Dr. Sima has disclosed that she is employed by Genentech, Inc.

This work was partially supported by the Goldstein Fund and Core Grant (P30CA008748) awards. This work was previously presented as a poster at the 2012 San Antonio Breast Cancer Symposium.

Correspondence: Anne A. Eaton, MS, Memorial Sloan Kettering Cancer Center, Department of Epidemiology and Biostatistics,

485 Lexington Avenue, 2nd Floor, New York, NY 10017.

E-mail: eatona@mskcc.org endorsement by NCCN or ANCC of any commercial products discussed/displayed in conjunction with the educational activity. Kristina M. Gregory, RN, MSN, OCN, is our nurse planner for this educational activity.

All clinicians completing this activity will be issued a certificate of participation. To participate in this journal CE activity: 1) review the learning objectives and author disclosures; 2) study the education content; 3) take the posttest with a $66 \%$ minimum passing score and complete the evaluation at http://education.nccn.org/node/77808; and 4) view/print certificate.

Release date: January 1, 2016; Expiration date: January 1, 2017

\section{Learning Objectives}

Upon completion of this activity, participants will be able to:

- Outline the "off-label" use of drugs in oncology

- Summarize the importance of adherence to clinical guidelines and/or FDA-approved label for prescribing drugs and providing optimal care

\section{EDITOR}

Kerrin M. Green, MA, Assistant Managing Editor, JNCCN-Journal of the National Comprehensive Cancer Network

Ms. Green has disclosed that she has no relevant financial relationships.

\section{CE AUTHORS}

Deborah J. Moonan, RN, BSN, Director, Continuing Education, has disclosed that she has no relevant financial relationships.

Ann Gianola, MA, Manager, Continuing Education Accreditation \& Program Operations, has disclosed that she has no relevant financial relationships.

Kristina M. Gregory, RN, MSN, OCN, Vice President, Clinical Information Operations, has disclosed that she has no relevant financial relationships. Rashmi Kumar, PhD, Senior Manager, Clinical Content, has disclosed that she has no relevant financial relationships. 


\section{Background}

When a new drug is developed, the manufacturer must apply for approval from the FDA Center for Drug Evaluation and Research (CDER) before it can enter the market. The FDA grants approval for a specific setting (indication), including patient population, dosage, route of administration, and other criteria, based on efficacy and safety data. After approval, physicians may prescribe the drug for unapproved indications ("off-label use"), and doing so may in fact be standard medical practice, especially in the oncology setting. ${ }^{1,2}$

A 2006 report describing prescribing patterns of 160 commonly used drugs found an estimated 150 million off-label mentions ( $21 \%$ of overall use) and that $73 \%$ of off-label prescriptions had little or no scientific support. ${ }^{1}$ Despite concerns about patient safety and costs to the health care system, little is known about the frequency of off-label use in oncology. A study conducted in 1991 by the US General Accounting Office (GAO), which was based on a survey of 681 oncologists, revealed that $33 \%$ of all anticancer drug administrations, were off-label and $56 \%$ of patients received at least one off-label drug. ${ }^{3}$ A total of $28 \%$ of patients received a drug that did not have scientific support. Estimates from a more recent report on more than 2 million administrations of 10 intravenous chemotherapies were similar: $30 \%$ of use was off-label. ${ }^{4}$

The option to use drugs off-label preserves the oncologists' autonomy to consider their patients' individual medical status, allows accumulation of realworld efficacy and safety data, and makes novel drugs available in a timely manner and for cancer types with limited viable treatment options. However, off-label use can have negative consequences if the risk/benefit profile of the drug is not well established in the off-label setting, possibly resulting in increased toxicities. ${ }^{2}$ This problem may be exacerbated in older adults given the underrepresentation of this population in cancer registration trials, leading to lack of available data to guide treatment decisions. ${ }^{5}$ Furthermore, financial incentives for doctors to prescribe new and costly medications encourage the use of treatments that extrapolate the label indication. ${ }^{6,7}$ In the current economic environment, in which the need to control health care costs is universally recognized, use of offlabel drugs without proven efficacy or comprehensive safety evaluation may be a target for cutting costs.
NCCN is an alliance of 26 US cancer centers whose mission is to improve "the quality, effectiveness, and efficiency of cancer care so that patients can live better lives." ${ }^{8}$ The organization publishes the NCCN Clinical Practice Guidelines in Oncology (NCCN Guidelines) that serve as established measures for appropriate disease management in the oncology community. The guidelines also influence the Centers for Medicare \& Medicaid Services (CMS) reimbursement of chemotherapy treatments; since 1993, Medicare has been required to cover offlabel uses mentioned in accepted drug compendia (among which the NCCN Guidelines are central) or with scientific support in certain peer-reviewed journals. ${ }^{9}$ Even in the absence of FDA labeling, treatment in accordance with NCCN Guidelines is widely regarded as "appropriate"; thus, it is important to differentiate between off-label use that is and is not included in the NCCN Guidelines. In their 2013 report, Conti et $\mathrm{al}^{4}$ found that approximately half of the off-label use identified was included in the NCCN Guidelines.

This study sought to estimate the prevalence of off-label use of chemotherapies and to determine whether off-label use is associated with increased rates of hospitalization and emergency department (ED) admission in a cohort of elderly Medicare beneficiaries diagnosed with breast cancer. To focus on use that could be considered "inappropriate," we differentiate between off-label use in agreement with NCCN Guidelines versus off-label use without scientific support (ie, not included in NCCN Guidelines).

\section{Methods}

\section{Data Source and Cohort Definition}

The SEER-Medicare linked database (including cancer diagnoses through 2007 and Medicare claims through 2008) was used. ${ }^{10}$ Female Medicare beneficiaries aged 65 years and older residing in geographic areas contained in the SEER registries and diagnosed with a first primary invasive breast cancer between 2000 and 2007 were identified. Patients were excluded for any of the following: diagnosis made at time of death, missing month of diagnosis, prior cancer diagnosis, enrollment in an $\mathrm{HMO}$, and/or lack of continuous Part B Medicare enrollment in the first 6 months after diagnosis. To restrict our analysis to pa- 
Off-Label Use of Chemotherapy

tients whose treatment followed standard guidelines, we excluded patients with stage I-III disease who did not undergo surgical resection within 4 months of diagnosis (or within 4 months of completion of neoadjuvant therapy), and patients diagnosed with stage IV disease who underwent surgery.

\section{FDA Approval and NCCN Guideline Recommendation}

Drugs approved for breast cancer were identified and available labels were compiled. ${ }^{11,12}$ Approval dates and breast cancer indications (adjuvant and/or metastatic; if metastatic, first line and/or after failure of another agent) were recorded for each label version. The same information was compiled from all versions of the NCCN Guidelines for Breast Cancer from 2000 through 2008. ${ }^{13-27}$ Drugs approved and/ or included in the NCCN Guidelines in the adjuvant setting were also considered to be approved ("supported") in the neoadjuvant setting, because separate approvals ("support") specifically for the neoadjuvant setting were not standard in this era. FDA approval and NCCN Guideline information is displayed in Figure 1.

\section{Characterization of Chemotherapy Use}

We identified Medicare claims associated with intravenous chemotherapy administration after breast cancer diagnosis and before a secondary cancer diagnosis. The specific agent was identified using the Healthcare Common Procedure Coding System (HCPCS) J$\operatorname{code}^{28}$ (see supplemental eAppendix 1, available with this article at JNCCN.org). Patients were considered to have received chemotherapy if at least one chemotherapy claim was identified within 4 months of surgery (stage I-III) or diagnosis (stage IV).

The Medicare claims data contain information on each agent administered (including the date of administration) but do not indicate whether the agent is part of a combination regimen or whether it is being used in the neoadjuvant, adjuvant, firstline or later-line setting. Thus, we developed an algorithm to separate claims into regimen lines, which we defined as a period of time during which a patient was being treated with a specific single-agent or combination regimen. Each patient's first regimen line started on the first day chemotherapy was administered. Any additional agents given in the next 15 days were considered to be part of a combination regimen. After 15 days, if a new agent was given, this was considered to indicate the start of the subsequent regimen line, except in the case of established sequential regimens (supplemental eAppendix 2); in these cases a new agent was counted as part of the same regimen line, because the regimen is designed to contain multiple phases. ${ }^{29}$ (For example, if a patient received doxorubicin/cyclophosphamide followed by docetaxel, this would count as a single regimen line). The same algorithm was used to define each subsequent regimen line of intravenous chemotherapy. Examples demonstrating the algorithm are shown in Figure 2. In the metastatic setting, each change in regimen represents a higher line of treatment; in the adjuvant setting, the first treatment given after surgery is referred to as initial adjuvant, and treatment following a deviation from initial adjuvant regimen
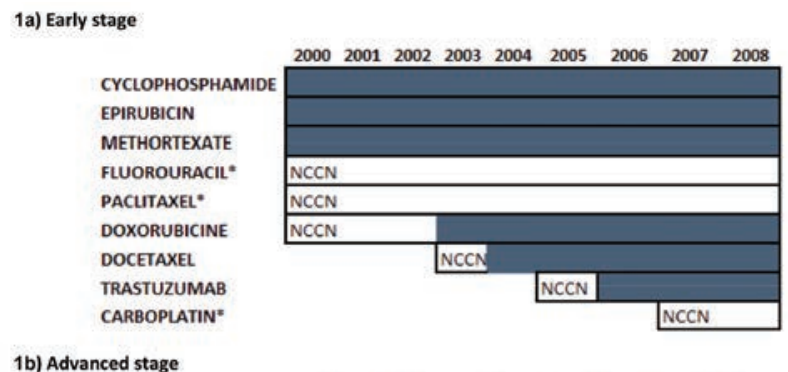

1b) Advanced stage

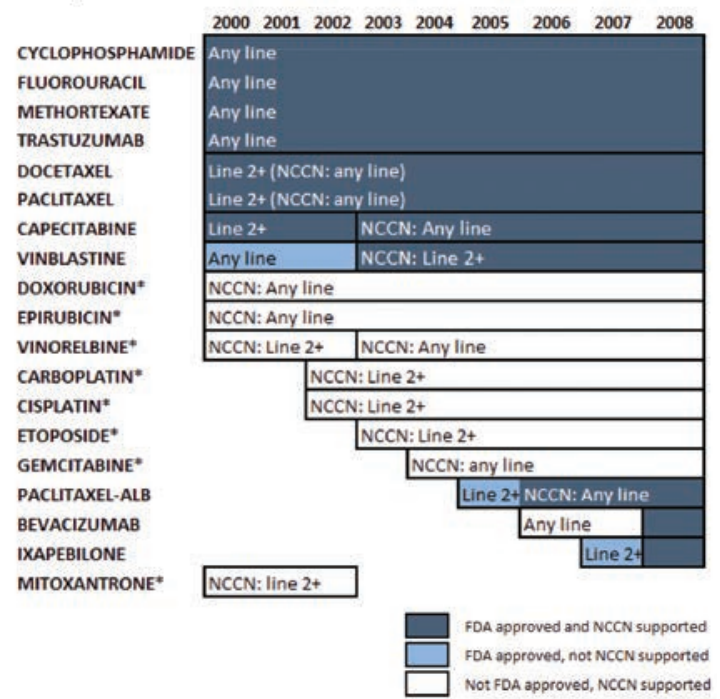

Figure 1. FDA approval and NCCN Guideline information by year for intravenous chemotherapies. Approval timelines for (A) adjuvant treatment of early-stage breast cancer (stage I-III); (B) advancedstage breast cancer (stage IV metastatic). Dark blue indicates years during which the agent was FDA-approved and included in the NCCN Guidelines for Breast Cancer, light blue indicates years during which the agent was FDA-approved but not included in the NCCN Guidelines, and white indicates years during which the agent was included in the NCCN Guidelines but not FDA-approved. Blank spaces indicate years during which the agent was neither approved nor supported.

*Agent was never FDA-approved for that stage of disease at any time during the study period. 
is referred to as altered adjuvant. All agents administered preoperatively were considered to be part of a single neoadjuvant regimen line. For stages I-III, in order to limit our analysis to treatment of the primary tumor and to avoid capturing treatment after disease recurrence, the end of adjuvant therapy was identified when Medicare claims did not indicate chemotherapy administration for at least 120 days. We assumed that treatment breaks of up to 120 days could be due to toxicity or other delays, but that a longer break would indicate the completion of initial chemotherapy, and that additional treatment after such a break may be for metastatic or recurrent disease.

Each regimen line was classified into one of the following indication categories based on the stage and line of chemotherapy:

- On-label: All chemotherapies included in the regimen line were consistent with the FDA label indication.

- Off-label/Included in NCCN Guidelines ("OffLabel/Supported"): All chemotherapies included in the regimen line were included in the NCCN Guidelines, and at least one chemotherapy included in the regimen line was not consistent with the FDA label indication.

- Off-label/Not included in NCCN Guidelines (“Off-Label/Unsupported"): At least one chemotherapy included in the regimen line was not consistent with the FDA label indication and was not included in the NCCN Guidelines

Indication category determinations were made based on the versions of FDA labels and NCCN Guidelines in use 90 days following the date of administration, allowing for uses of a drug shortly before

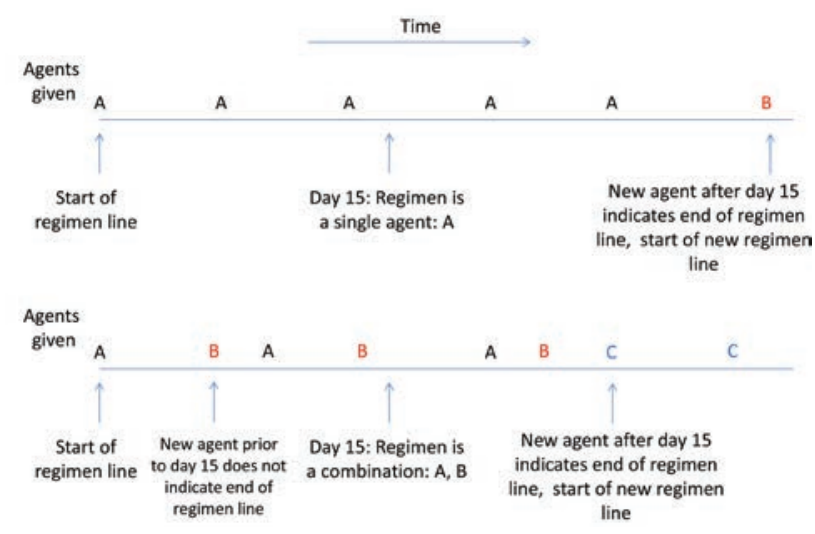

Figure 2. Two sample scenarios demonstrating the algorithm used to separate dated chemotherapy claims into regimen lines. A, B, and C represent different agents. approval/inclusion in the NCCN Guidelines to be counted as approved/included. For off-label/unsupported drug administrations, the reason the drug was not supported was classified as either: (1) drug was never included in the NCCN Guidelines for Breast Cancer, ${ }^{13-27}$ (2) use was more than 90 days before inclusion in the NCCN Guidelines, or (3) drug was used in a stage or line outside of NCCN recommendations. To be conservative, J-code J9999 ("Not otherwise classified antineoplastic drugs") was considered on-label.

\section{Comparison of Hospitalization and ED Admission Rates}

Each off-label/unsupported regimen line was matched with one off-label/supported regimen line and one on-label regimen line. Matching factors were age, line of chemotherapy, number of prior comorbidities, stage at diagnosis, and history of prior hospitalizations/ED admissions, as categorized in supplemental eTable $1^{30}$

A hospitalization or ED admission was assigned to a regimen line if it occurred on or after day 16 of a regimen line (when all agents comprising a combination regimen would have been started) and before the start of a new regimen line (before date of surgery for neoadjuvant lines), or within 30 days of the last chemotherapy administration if no subsequent lines were initiated. Using the matched regimen lines, rates of hospitalization and/or ED admission and corresponding Wald 95\% CIs were compared between indication categories, overall and by stage. Wald type III $P$ values were obtained using conditional logistic regression. Analyses investigating the distribution of indication category by stage and line of chemotherapy were descriptive and tests were not conducted. All statistical analysis was performed using SAS 9.4 (SAS Institute, Cary, NC).

\section{Results}

Figures $1 \mathrm{~A}$ and $\mathrm{B}$ list drugs that are FDA-approved and/or included in the NCCN Guidelines for Breast Cancer $^{13-27}$ between 2000 and 2008, and their stagespecific and line-specific indications. Notably, more drugs are approved for advanced-stage than for early-stage disease, and in the advanced-stage setting, some drugs are only approved in the second line or later. 
Off-Label Use of Chemotherapy

\section{Study Cohort}

The initial cohort consisted of 78,824 women. A total of $17 \%(n=13,347)$ received chemotherapy $(5 \%$, $33 \%, 50 \%$, and $21 \%$ for stages I-IV, respectively) and are included in the analyses. The breakdown by demographic and clinical factors is presented in supplemental eTable 1.

\section{Prevalence of Off-Label Use}

Use by indication category is presented in Table 1. Overall, only $25 \%$ of all regimen lines consisted exclusively of on-label drugs. Most regimen lines (64\%) were off-label/supported. A total of $11 \%$ of all regimens were off-label/unsupported, with higher rates of such use in patients with stage III $(16 \%)$ or IV $(12 \%)$ disease.

Initial adjuvant regimens were rarely off-label/ unsupported (7\%). However, following a change in adjuvant regimen, prevalence of inappropriate use increases dramatically to $34 \%$. The use of off-label/ unsupported regimens in the neoadjuvant setting was $15 \%$. Regimens used in advanced disease were more likely to be off-label/unsupported if used in the first line of chemotherapy (rate of off-label/unsupported use: $17 \%$ vs $6 \%$ in the second line or higher), likely the reflection of the fact that a large number of agents are approved and/or included in the NCCN Guidelines for use as second-line therapy, but not as first-line therapy (Figure 1B). Rates of off-label/ unsupported and off-label/supported use by age and comorbidity index are shown in Table 1.

For chemotherapy drugs that were part of at least 24 regimen lines, Figure 3 presents the proportion of off-label/unsupported use, as a function of the total use. Six of the most commonly used agents (cyclophosphamide, doxorubicin, 5-FU, methotrexate, paclitaxel, epirubicin), accounting for $81 \%$ of the total drug use, were FDA-approved and/or included in the NCCN Guidelines for all stages and lines of chemotherapy. For docetaxel and trastuzumab (13\% of total use), $14 \%$ and $16 \%$ of use, respectively, was off-label/ unsupported. (Although both drugs were included in the NCCN Guidelines for all stages and lines by 2005, they were not included for early-stage breast cancer in the early part of the study period.) These 2 drugs alone accounted for $38 \%$ of the off-label/unsupported use. The remaining $60 \%$ of off-label/unsupported drug use was due to drugs that were rarely prescribed in this cohort, some of which have never been supported for breast cancer (eg, vincristine, mi- tomycin, cytarabine, rituximab, fludarabine, and irinotecan). Most off-label/unsupported use (76\%) was due to drug use outside of the recommended stage and/or line (including docetaxel and trastuzumab), whereas drugs never supported for breast cancer accounted for $19 \%$ of the off-label/unsupported use and $1 \%$ of the total use. Use of drugs more than 90 days before inclusion in the NCCN Guidelines was not common and accounted for only $5 \%$ of off-label/ unsupported use.

\section{Hospitalization and ED Admission}

In the matched analysis, a hospitalization or ED admission occurred in 32\% (95\% CI, 29-34) of offlabel/unsupported regimen lines, compared with $27 \%$ (95\% CI, 25-29) of off-label/supported regimen lines and 25\% (95\% CI, 22-27) of on-label regimen lines $(P<.0001)$. Figure 4 presents the event rates by indication category for each disease stage. On-label lines generally had the lowest event rate, with the exception of stage IV, for which on-label lines had the highest rate $(53 \%)$, although rates of hospitalization/ED admission were not significantly different $(P=.241)$. Of 138 on-label regimen lines used in the stage IV setting, 54 (39\%, compared with 9\% of all use) consisted of single-agent trastuzumab and 33 (24\%, compared with $3 \%$ of all use) consisted of the combination regimen cyclophosphamide, 5-FU, and methotrexate $(\mathrm{CMF})$. Both of these regimens were observed to have high rates of hospitalization and ED admission (trastuzumab, 61\%; CMF, 55\%), which increased the event rate for on-label lines in the stage IV setting.

\section{Discussion}

We evaluated the prevalence of off-label chemotherapy use among Medicare beneficiaries diagnosed with breast cancer and the rate of ED visits/hospitalizations among patients receiving this type of treatment. Overall, $11 \%$ of the lines of therapy included one or more drugs whose use was not in agreement with their FDA label indication and not included in the NCCN Guidelines. The low prevalence of off-label/unsupported use confirms prior reports and provides reassurance regarding the appropriateness of the therapeutic decisions made in the medical community. ${ }^{4}$

We found that most therapy regimens (64\%) were prescribed in a setting outside the FDA label 
Eaton et al

\begin{tabular}{|c|c|c|c|c|c|}
\hline & & Off-Label/Unsupported & Off-Label/Supported & On-Label & Total \\
\hline \multirow[t]{5}{*}{ All regimen lines } & & $1,749(11 \%)$ & $10,391(64 \%)$ & $3,987(25 \%)$ & 16,127 \\
\hline & Stage I & $239(9 \%)$ & $1,661(61 \%)$ & $803(30 \%)$ & 2,732 \\
\hline & Stage II & $775(9 \%)$ & $5,754(67 \%)$ & $2,014(24 \%)$ & 8,543 \\
\hline & Stage III & $567(16 \%)$ & $2,000(57 \%)$ & $920(26 \%)$ & 3,487 \\
\hline & Stage IV & $168(12 \%)$ & $976(70 \%)$ & $250(18 \%)$ & 1,394 \\
\hline \multicolumn{6}{|l|}{ Stage I-III } \\
\hline & Neoadjuvant & $171(15 \%)$ & $577(50 \%)$ & $412(36 \%)$ & 1,160 \\
\hline & Initial adjuvant & $861(7 \%)$ & $7,985(67 \%)$ & $3,113(26 \%)$ & 11,959 \\
\hline & Altered adjuvant ${ }^{a}$ & $549(34 \%)$ & $853(53 \%)$ & $212(13 \%)$ & 1,614 \\
\hline \multicolumn{6}{|l|}{ Stage IV } \\
\hline & Line 1 & $133(17 \%)$ & $534(70 \%)$ & $96(13 \%)$ & 763 \\
\hline & Line 2 & $19(6 \%)$ & $230(70 \%)$ & $78(24 \%)$ & 327 \\
\hline & Line 3+ & $16(5 \%)$ & $212(70 \%)$ & $76(25 \%)$ & 304 \\
\hline \multicolumn{6}{|l|}{ Age, y } \\
\hline & $>65-70$ & $525(10 \%)$ & $3,534(64 \%)$ & $1,469(27 \%)$ & 5,528 \\
\hline & $>70-75$ & $546(11 \%)$ & $3,166(65 \%)$ & $1,165(24 \%)$ & 4,877 \\
\hline & $>75-80$ & $297(10 \%)$ & $1,940(67 \%)$ & $674(23 \%)$ & 2,911 \\
\hline & $>80-85$ & $162(16 \%)$ & $633(62 \%)$ & $231(23 \%)$ & 1,026 \\
\hline & $>85$ & $47(22 \%)$ & $115(53 \%)$ & $53(25 \%)$ & 215 \\
\hline \multicolumn{6}{|c|}{ Charlson comorbidity index } \\
\hline & 0 & $1,184(11 \%)$ & $7,194(66 \%)$ & $2,592(24 \%)$ & 10,970 \\
\hline & 1 & $246(10 \%)$ & $1,538(62 \%)$ & $704(28 \%)$ & 2,488 \\
\hline & $>1$ & $133(13 \%)$ & $588(60 \%)$ & $266(27 \%)$ & 987 \\
\hline
\end{tabular}

anitial adjuvant was the first treatment given after surgery; altered adjuvant refers to treatment following a deviation from initial adjuvant regimen. bonly patients diagnosis at age $66+$ are included as 1 year of prediagnosis claims were required to ascertain comorbidity score.

indication but included in the NCCN Guidelines. This reflects the fact that registration trials tend to be undertaken in well-defined, specific populations that maximize the chance of therapeutic success, leading to narrow label indications. In contrast, once the drug enters the market, the opinion of leaders in the medical community, reflected in professional guidelines and the scientific literature, is more influential on drug use than the label. Because off-label use in accordance with professional guidelines is generally covered by insurance, there is little incentive for drug manufacturers to go through a cumbersome FDA approval process to update the label indications. Furthermore, performing well-controlled trials for all of the settings in which a drug may be active (eg, site, stage, disease combinations) is not feasible, and is not necessary with good-quality retrospective data. Interestingly, the rate of off-label/supported use was much lower in the report by Conti et $\mathrm{al}^{4}$ ( $14 \%$ of administrations), possibly reflecting the fact that their analysis excluded agents with expired patents.

In the adjuvant setting, we found small but nonnegligible increases in the risk of hospitalization and ED admission as we moved from on-label to off label/ supported to off-label/unsupported regimen lines. To our knowledge, this is the first comparative evaluation of outcomes after treatment with off-label chemotherapy. We hypothesize that the lack of rigorous scientific scrutiny that accompanies off-label/unsupported use translates into limited but real added toxicity burden. An alternative explanation is that use of off-label/unsupported drugs could be a marker for suboptimal care.

In contrast, among patients with stage IV disease, we observed the highest hospitalization and ED admission rates for on-label regimens, more than half of which consisted of trastuzumab monotherapy or 
Off-Label Use of Chemotherapy

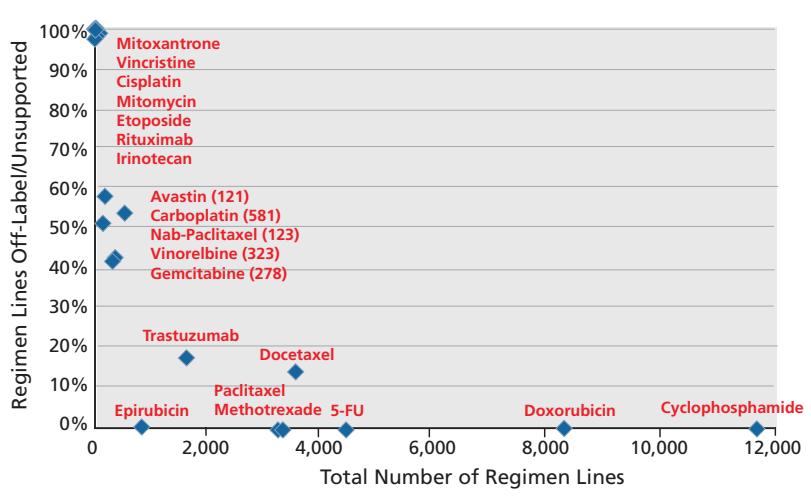

Figure 3. Percent of regimen lines off-label/unsupported versus total number of regimen lines, by agent. Only agents that were used in at least 24 regimen lines are included. Most agents were either used in very few regimen lines but with almost $100 \%$ of uses being offlabel, or used in many regimen lines with almost $100 \%$ of uses being on-label. For agents with $40 \%$ to $60 \%$ of uses off-label, the total number of regimen lines in which they were used is shown next to the agent name.

CMF, regimens usually associated with milder toxicity profiles. This could be due to doctors selecting safer regimens for patients more prone to adverse events. Patients with stage I-III disease at an increased risk of adverse events may also tend to be treated with less toxic regimens; this would lead to conservative estimates of the excess toxicity associated with off-label/unsupported regimens, because safer regimens with betterunderstood toxicity profiles would tend to be on-label.

Our analysis has several limitations. The generalizability of results is limited to older Medicare beneficiaries with breast cancer. The rates of off-label use might be higher in younger, commercially insured patients or in other cancers, in which a more limited number of drugs that are FDA-approved and included in the NCCN Guidelines may lead to more therapeutic experimenting. Furthermore, although SEER-Medicare files allow identification of chemotherapy use with high accuracy, identification of specific agents has been shown to have sensitivity in the range of $70 \%$ to $80 \%$; drugs used off-label and outside of professional guidelines might be especially underreported. ${ }^{31}$ Together, these suggest that the rates observed are conservative estimates of off-label/unsupported use.

The results are also not generalizable to endocrine and oral therapies, because these were not covered before the passage of Medicare Part D, and thus reimbursement data were not available. Relatedly, such therapies were not accounted for when determining line of therapy; however, we believe that the amount of previous intravenous chemotherapy still captures an important patient characteristic that may affect our outcomes.

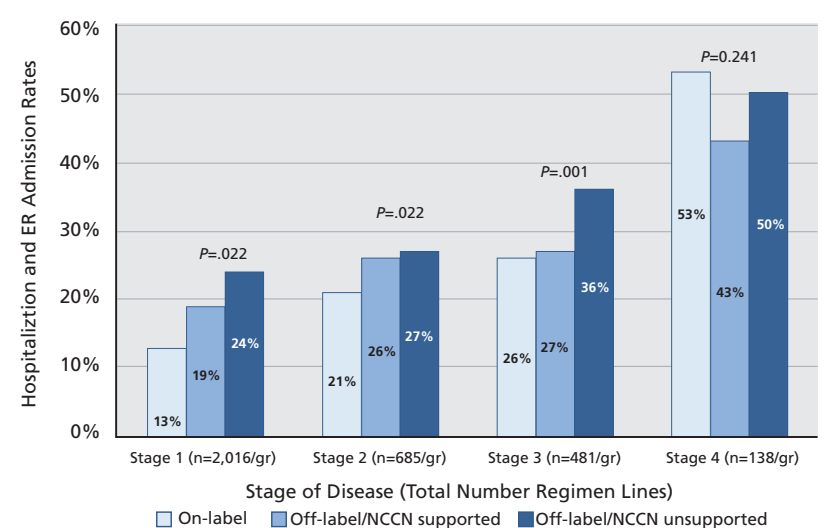

Figure 4. Matched analysis of hospitalization and emergency department admission rates by indication category and stage.

Furthermore, SEER does not collect information on cancer recurrence, so it is possible that some patients with nonmetastatic disease experienced progression to metastatic disease and were treated with a drug that was off-label (not recommended) for their initial disease but on-label (recommended) for their current disease at the time of treatment. To capture only initial treatment and exclude treatment after recurrence, we stopped following patients with stage I-III disease after they had a period of 120 days without chemotherapy administration. The detection of adverse events using claims data is difficult, and it is impossible to definitively attribute toxicities to chemotherapy, especially in advanced-stage disease. Hence we focused on events (hospitalizations and ED admissions) that are serious and can be reliably identified, and we carefully matched off-label and onlabel regimens by factors that may influence the risk of toxicity.

Finally, we were not able to account for different toxicity profiles inherent to different agents, because the sample size prevented matching by specific agent administered or for varying propensity to receive off-label treatment.

Overall, we found that off-label/unsupported use was uncommon and that use of chemotherapy regimens that are off-label but have scientific support was surprisingly common, representing $64 \%$ of all use. We found slightly increased rates of hospitalization and ED admission in off-label/supported regimens. Although off-label/unsupported use has traditionally been an obvious target for cost-containment and quality-of-care improvement, the high prevalence of off-label/supported use should not be ignored. ${ }^{32}$ This large segment of use likely consists of therapies that fall across a spectrum in terms of safety. With the recent 
paradigm shift toward treatments directed at molecular targets and immunotherapies, which are expected to have activity across different cancer sites (and are extremely expensive), the off-label/supported share of use will likely increase. Given that the NCCN Guidelines appear to be central in chemotherapy use, safety evaluation of the off-label, guideline-recommended indications is critical. ${ }^{32}$ In fact, although NCCN has traditionally based its guidelines on efficacy without explicitly addressing toxicity or cost, plans were recently announced to incorporate both of these into future guidelines. ${ }^{33}$ The NCCN has developed NCCN Evidence Blocks, which visually summarize information about efficacy, safety, quality and consistency of evidence and affordability, and these have been incorporated into guidelines for chronic myelogenous leukemia, kidney cancer and multiple myeloma and will be included in future guidelines for additional cancer types. ${ }^{34}$ The integration of this additional important information will help doctors and patients navigate the heterogenous space of off-label/supported therapy and make optimal treatment decisions.

\section{References}

1. Radley DC, Finkelstein SN, Stafford RS. Off-label prescribing among office-based physicians. Arch Intern Med 2006;166:1021-1026.

2. Stafford RS. Regulating off-label drug use-rethinking the role of the FDA. N Engl J Med 2008;358:1427-1429.

3. Report to the Chairman: Committee on Labor and Human Resources, US Senate: Off-Label Drugs: Reimbursement Policies Constrain Physicians In Their Choice Of Cancer Therapies. Washington DC: United States General Accounting Office; 1991. GAO/PEMD-21-14. Available at: http://www.gao.gov/assets/160/151121.pdf. Accessed December 8, 2015.

4. Conti RM, Bernstein AC, Villaflor VM, et al. Prevalence of off-label use and spending in 2010 among patent-protected chemotherapies in a populationbased cohort of medical oncologists. J Clin Oncol 2013;31:1134-1139.

5. Scher KS, Hurria A. Under-representation of older adults in cancer registration trials: known problem, little progress. J Clin Oncol 2012;30:2036-2038.

6. de Souza JA, Alexander GC. Unsupported off-label use of cancer therapies: new challenges in the era of biopharmaceuticals. Expert Rev Pharmacoecon Outcomes Res 2011;11:495-498.

7. Howard DH, Bach PB, Berndt ER, Conti RM. Pricing in the market for anticancer drugs. NBER Working Paper No. 20867. January 2015. Available at: http://www.nber.org/papers/w20867. Accessed December 8, 2015.

8. About NCCN. National Comprehensive Cancer Network Web site. Available at: http://www.nccn.org/about/default.aspx. Accessed April 29, 2015.

9. American Society of Clinical Oncology, Cancer Policy and Clinical Affairs. Reimbursement for cancer treatment: coverage of off-label drug Affairs. Reimbursement for cancer treatment:
indications. J Clin Oncol 2006;24:3206-3208.

10. Warren JL, Klabunde CN, Schrag D, et al. Overview of the SEERMedicare data: content, research applications, and generalizability to the United States elderly population. Med Care 2002;40(Suppl):IV3-18.

11. National Cancer Institute. Drugs approved for breast cancer. National Cancer Institute Web site. Available at: http://www.cancer.gov/ cancertopics/druginfo/breastcancer. Accessed April 29, 2015.

12. Drugs@FDA: FDA approved drug products. US Food and Drug Administration Web site. Available at: http://www.accessdata.fda.gov/ scripts/cder/drugsatfda/. Accessed April 29, 2015.
13. Carlson RW, Anderson BO, Bensinger W, et al. NCCN Practice Guidelines for Breast Cancer, version 1.2000. Released June 1, 2000. To view the most recent version of these guidelines, visit NCCN.org.

14. Carlson RW, Anderson BO, Bensinger W, et al. NCCN Practice Guidelines in Oncology for Breast Cancer, version 1.2002. Released November 6, 2001. To view the most recent version of these guidelines, visit NCCN.org.

15. Carlson RW, Anderson BO, Bensinger W, et al. NCCN Practice Guidelines in Oncology for Breast Cancer, version 2.2002. Released March 15, 2002. To view the most recent version of these guidelines, visit NCCN.org.

16. Carlson RW, Anderson BO, Bensinger W, et al. NCCN Practice Guidelines in Oncology for Breast Cancer, version 1.2003. Released October 29, 2002. To view the most recent version of these guidelines, visit NCCN.org.

17. Carlson RW, Anderson BO, Bensinger W, et al. NCCN Practice Guidelines in Oncology for Breast Cancer, version 2.2003. Released May 19, 2003. To view the most recent version of these guidelines, visit NCCN.org.

18. Carlson RW, Anderson BO, Bensinger W, et al. NCCN Practice Guidelines in Oncology for Breast Cancer, version 3.2003. Released November 14, 2003. To view the most recent version of these guidelines, visit NCCN.org.

19. Carlson RW, Anderson BO, Bensinger W, et al. NCCN Practice Guidelines in Oncology for Breast Cancer, version 1.2005. Released February 10, 2005. To view the most recent version of these guidelines, visit NCCN.org.

20. Carlson RW, Anderson BO, Burstein HJ, et al. NCCN Practice Guidelines in Oncology for Breast Cancer, version 2.2005. Released May 31, 2005. To view the most recent version of these guidelines, visit NCCN.org.

21. Carlson RW, Anderson BO, Burstein HJ, et al. NCCN Practice Guidelines in Oncology for Breast Cancer, version 1.2006. Released November 2, 2005. To view the most recent version of these guidelines, visit NCCN.org.

22. Carlson RW, Anderson BO, Burstein HJ, et al. NCCN Practice Guidelines in Oncology for Breast Cancer, version 2.2006. Released December 5, 2005. To view the most recent version of these guidelines, visit NCCN.org.

23. Carlson RW, Anderson BO, Burstein HJ, et al. NCCN Practice Guidelines in Oncology for Breast Cancer, version 1.2007. Released January 30, 2007. To view the most recent version of these guidelines, visit NCCN.org.

24. Carlson RW, Anderson BO, Burstein HJ, et al. NCCN Practice Guidelines in Oncology for Breast Cancer, version 2.2007. Released March 28, 2007. To view the most recent version of these guidelines, visit NCCN.org.

25. Carlson RW, Allred DC, Anderson BO, et al. NCCN Practice Guidelines in Oncology for Breast Cancer, version 1.2008. Released December 12, 2007. To view the most recent version of these guidelines, visit NCCN.org.

26. Carlson RW, Allred DC, Anderson BO, et al. NCCN Practice Guidelines in Oncology for Breast Cancer, version 2.2008. Released January 3, 2008. To view the most recent version of these guidelines, visit NCCN.org.

27. Carlson RW, Allred DC, Anderson BO, et al. NCCN Practice Guidelines in Oncology for Breast Cancer, version 1.2009. Released December 2, 2008. To view the most recent version of these guidelines, visit NCCN.org.

28. Alpha-Numeric HCPCS Items. Centers for Medicaid and Medicare Services Web site. Available at: https:/www.cms.gov/Medicare/Coding/ HCPCSReleaseCodeSets/Alpha-Numeric-HCPCS-Items/2015-AlphaNumeric-HCPCS-File-\%C2\%A0.html. Accessed December 15, 2015.

29. The NCCN Chemotherapy Order Templates (NCCN Templates). Available at: NCCN.org. Accessed April 29, 2015. To view the most recent and complete version of the NCCN Templates, go to NCCN.org.

30. Deyo RA, Cherkin DC, Ciol MA. Adapting a clinical comorbidity index for use with ICD-9-CM administrative databases. J Clin Epidemiol 1992;45:613-619.

31. Lund JL, Stürmer T, Harlan LC, at al. Identifying specific chemotherapeutic agents in Medicare data: a validation study. Med Care 2013;51:e27-34.

32. Burstein H. Off-label use of oncology drugs: too much, too little, or just right? J Natl Compr Canc Netw 2013;11:505-506.

33. Helwick C. 20 years of NCCN: the best is yet to come. A conversation with Robert W. Carlson, MD. The ASCO Post 2015;6. Available at: http:// www.ascopost.com/issues/april-25,-2015/20-years-of-nccn-the-best-is-yetto-come.aspx. Accessed April 29, 2015.

34. NCCN Clinical Practice Guidelines in Oncology (NCCN Guidelines) with NCCN Evidence Blocks. National Comprehensive Cancer Network Web site. Available at: http://www.nccn.org/evidenceblocks/. Accessed December 15, 2015. 
Off-Label Use of Chemotherapy

\section{Instructions for Completion}

To participate in this journal CE activity: 1) review the learning objectives and author disclosures; 2 ) study the education content; 3 ) take the posttest with a $66 \%$ minimum passing score and complete the evaluation at http://education.nccn.org/ node/77808; and 4) view/print certificate. After reading the article, you should be able to answer the following multiple-

\section{Posttest Questions}

1. What percentage of intravenous chemotherapy administered is "off-label" (ie, not FDA-approved for the indication used)?
a. Approximately $30 \%$
b. Approximately $50 \%$
c. Approximately $75 \%$

2. Medicare is required to cover

a. Off-label use of drugs listed in accepted drug compendia (which includes NCCN Guidelines and Compendia) choice questions. Credit cannot be obtained for tests completed on paper. You must be a registered user on NCCN.org. If you are not registered on NCCN.org, click on "New Member? Sign up here" link on the left hand side of the Web site to register. Only one answer is correct for each question. Once you successfully answer all posttest questions you will be able to view and/or print your certificate. Software requirements: Internet

b. Drugs with scientific support in certain peer-reviewed journals c. Both $a$ and $b$

3. True or False: In the matched analysis that was performed, hospitalization or emergency department admission rates with off-label regimens included

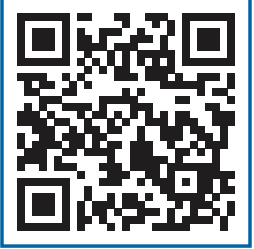
in the NCCN Guidelines were same as those treated with off-label regimens not included in the NCCN Guidelines. 
Supplemental online content for:

\section{Prevalence and Safety of Off-Label Use of Chemotherapeutic Agents in Older Patients With Breast Cancer: Estimates From SEER-Medicare Data}

Anne A. Eaton, MS; Camelia S. Sima, MD, MS; and Katherine S. Panageas, DrPH

J Natl Compr Canc Netw 2016;14(1):57-65

- eAppendix 1: J-Codes Representing Intravenous Chemotherapy

- eAppendix 2: Established Sequential Adjuvant Chemotherapy Regimens for Breast Cancer

- eTable 1: Patient Characteristics 
eAppendix 1: J-Codes Representing Intravenous Chemotherapy

\begin{tabular}{|c|c|c|c|}
\hline J-Code & Agent & J-Code & Agent \\
\hline J9000 & Injection, doxorubicin $\mathrm{HCl}, 10 \mathrm{mg}$ & \multirow[t]{2}{*}{$J 9165$} & \multirow{2}{*}{$\begin{array}{l}\text { Injection, diethylstilbestrol diphosphate, } 250 \\
\text { mg }\end{array}$} \\
\hline \multirow[t]{2}{*}{ J9001 } & \multirow{2}{*}{$\begin{array}{l}\text { Injection, doxorubicin } \mathrm{HCl} \text {, all lipid } \\
\text { formulations, } 10 \mathrm{mg}\end{array}$} & & \\
\hline & & J9170 & Injection, docetaxel, $20 \mathrm{mg}$ \\
\hline J9010 & Injection, alemtuzumab, $10 \mathrm{mg}$ & J9171 & Injection, docetaxel, 1 mg \\
\hline$J 9015$ & Injection, aldesleukin, per single use vial & J9175 & Injection, Elliotts' B solution, $1 \mathrm{ml}$ \\
\hline $\mathrm{J} 9017$ & Injection, arsenic trioxide, $1 \mathrm{mg}$ & J9178 & Injection, epirubicin $\mathrm{HCl}, 2 \mathrm{mg}$ \\
\hline J9020 & Injection, asparaginase, 10,000 units & J9179 & Injection, eribulin mesylate, $0.1 \mathrm{mg}$ \\
\hline$J 9025$ & Injection, azacitidine, $1 \mathrm{mg}$ & J9180 & Epirubicin $\mathrm{HCl}, 50 \mathrm{mg}$ \\
\hline J9027 & Injection, clofarabine, $1 \mathrm{mg}$ & J9181 & Injection, etoposide, $10 \mathrm{mg}$ \\
\hline J9031 & BCG (intravesical) per instillation & J9182 & Etoposide, $100 \mathrm{mg}$ \\
\hline J9033 & Injection, bendamustine $\mathrm{HCl}, 1 \mathrm{mg}$ & J9185 & Injection, fludarabine phosphate, $50 \mathrm{mg}$ \\
\hline J9035 & Injection, bevacizumab, 10 mg & J9190 & Injection, fluorouracil, $500 \mathrm{mg}$ \\
\hline J9040 & Injection, bleomycin sulfate, 15 units & J9200 & Injection, floxuridine, $500 \mathrm{mg}$ \\
\hline J9041 & Injection, bortezomib, $0.1 \mathrm{mg}$ & J9201 & Injection, gemcitabine $\mathrm{HCl}, 200$ mg \\
\hline $\mathrm{J} 9043$ & Injection, cabazitaxel, 1 mg & $J 9202$ & Goserelin acetate implant, per 3.6 mg \\
\hline J9045 & Injection, carboplatin, 50 mg & $J 9206$ & Injection, irinotecan, $20 \mathrm{mg}$ \\
\hline $\mathrm{J} 9050$ & Injection, carmustine, $100 \mathrm{mg}$ & J9207 & Injection, ixabepilone, $1 \mathrm{mg}$ \\
\hline$J 9055$ & Injection, cetuximab, 10 mg & J9208 & Injection, ifosfamide, $1 \mathrm{~g}$ \\
\hline $\mathrm{J} 9060$ & Injection, cisplatin, powder or solution, $10 \mathrm{mg}$ & J9209 & Injection, mesna, $200 \mathrm{mg}$ \\
\hline$J 9062$ & Cisplatin, $50 \mathrm{mg}$ & J9211 & Injection, idarubicin $\mathrm{HCl}, 5 \mathrm{mg}$ \\
\hline$J 9065$ & Injection, cladribine, per $1 \mathrm{mg}$ & \multirow[t]{2}{*}{$J 9212$} & \multirow{2}{*}{$\begin{array}{l}\text { Injection, interferon alfacon-1, recombinant, } 1 \\
\text { mcg }\end{array}$} \\
\hline J9070 & Cyclophosphamide, $100 \mathrm{mg}$ & & \\
\hline$J 9080$ & Cyclophosphamide, $200 \mathrm{mg}$ & J9213 & $\begin{array}{l}\text { Injection, interferon, alfa-2a, recombinant, } 3 \\
\text { million units }\end{array}$ \\
\hline $\mathrm{J} 9090$ & Cyclophosphamide, $500 \mathrm{mg}$ & \multirow{2}{*}{ J9214 } & Injection, interferon, alfa- $2 \mathrm{~b}$, recombinant 1 \\
\hline J9091 & Cyclophosphamide, $1 \mathrm{~g}$ & & million units \\
\hline J9092 & Cyclophosphamide, $2 \mathrm{~g}$ & \multirow[t]{2}{*}{$J 9215$} & \multirow{2}{*}{$\begin{array}{l}\text { Injection, interferon, alfa-N3, (human leukocyte } \\
\text { derived), 250,000 IU }\end{array}$} \\
\hline J9093 & Cyclophosphamide, lyophilized, $100 \mathrm{mg}$ & & \\
\hline$J 9094$ & Cyclophosphamide, lyophilized, $200 \mathrm{mg}$ & J9216 & Injection, interferon, gamma 1-b, 3 million units \\
\hline$J 9095$ & Cyclophosphamide, lyophilized, 500 mg & $\mathrm{J} 9217$ & Leuprolide acetate (for depot suspension), $7.5 \mathrm{mg}$ \\
\hline$J 9096$ & Cyclophosphamide, lyophilized, $1 \mathrm{~g}$ & J9218 & Leuprolide acetate, per $1 \mathrm{mg}$ \\
\hline$J 9097$ & Cyclophosphamide, lyophilized, $2 \mathrm{~g}$ & J9219 & Leuprolide acetate implant, $65 \mathrm{mg}$ \\
\hline J9098 & Injection, cytarabine liposome, 10 mg & $J 9225$ & Histrelin implant (Vantas), 50 mg \\
\hline J9100 & Injection, cytarabine, 100 mg & $\mathrm{J} 9226$ & Histrelin implant (Supprelin LA), 50 mg \\
\hline J9110 & Injection, cytarabine, $500 \mathrm{mg}$ & J9228 & Injection, ipilimumab, $1 \mathrm{mg}$ \\
\hline J9120 & Injection, dactinomycin, $0.5 \mathrm{mg}$ & J9230 & Injection, mechlorethamine $\mathrm{HCl}$, (nitrogen \\
\hline J9130 & Dacarbazine, $100 \mathrm{mg}$ & & mustard), $10 \mathrm{mg}$ \\
\hline J9140 & Dacarbazine, $200 \mathrm{mg}$ & 59240 & MEDROYPROGESTERONE ACETATE, 100 MG \\
\hline J9150 & Injection, daunorubicin, $10 \mathrm{mg}$ & J9245 & Injection, melphalan $\mathrm{HCl}, 50 \mathrm{mg}$ \\
\hline \multirow{2}{*}{ J9151 } & \multirow{2}{*}{$\begin{array}{l}\text { Injection, daunorubicin citrate, liposomal } \\
\text { formulation, } 10 \mathrm{mg}\end{array}$} & J9250 & Methotrexate sodium, $5 \mathrm{mg}$ \\
\hline & & J9260 & Methotrexate sodium, $50 \mathrm{mg}$ \\
\hline$J 9155$ & Injection, degarelix, $1 \mathrm{mg}$ & J9261 & Injection, nelarabine, 50 mg \\
\hline J9160 & Injection, denileukin diftitox, $300 \mathrm{mcg}$ & J9263 & Injection, oxaliplatin, $0.5 \mathrm{mg}$ \\
\hline
\end{tabular}


eAppendix 1: J-Codes Representing Intravenous Chemotherapy (cont.)

\begin{tabular}{|c|c|}
\hline J-Code & Agent \\
\hline J9264 & $\begin{array}{l}\text { Injection, paclitaxel protein-bound particles, } 1 \\
\text { mg }\end{array}$ \\
\hline J9265 & Injection, paclitaxel, 30 mg \\
\hline J9266 & Injection, pegaspargase, per single dose vial \\
\hline J9268 & Injection, pentostatin, $10 \mathrm{mg}$ \\
\hline J9270 & Injection, plicamycin, 2.5 mg \\
\hline J9280 & Mitomycin, 5 mg \\
\hline J9290 & Mitomycin, 20 mg \\
\hline J9291 & Mitomycin, $40 \mathrm{mg}$ \\
\hline J9293 & Injection, mitoxantrone $\mathrm{HCl}$, per 5 mg \\
\hline J9295 & POLYESTRADIOL PHOSPHATE 40 MG \\
\hline J9300 & Injection, gemtuzumab ozogamicin, 5 mg \\
\hline J9302 & Injection, ofatumumab, $10 \mathrm{mg}$ \\
\hline J9303 & Injection, panitumumab, $10 \mathrm{mg}$ \\
\hline J9305 & Injection, pemetrexed, $10 \mathrm{mg}$ \\
\hline J9307 & Injection, pralatrexate, $1 \mathrm{mg}$ \\
\hline J9310 & Injection, rituximab, 100 mg \\
\hline J9315 & Injection, romidepsin, $1 \mathrm{mg}$ \\
\hline J9320 & Injection, streptozocin, $1 \mathrm{~g}$ \\
\hline J9328 & Injection, temozolomide, $1 \mathrm{mg}$ \\
\hline J9330 & Injection, temsirolimus, 1 mg \\
\hline J9340 & Injection, thiotepa, $15 \mathrm{mg}$ \\
\hline J9350 & Injection, topotecan, 4 mg \\
\hline J9351 & Injection, topotecan, $0.1 \mathrm{mg}$ \\
\hline J9355 & Injection, trastuzumab, 10 mg \\
\hline J9357 & Injection, valrubicin, intravesical, 200 mg \\
\hline J9360 & Injection, vinblastine sulfate, $1 \mathrm{mg}$ \\
\hline J9370 & Vincristine sulfate, $1 \mathrm{mg}$ \\
\hline J9375 & Vincristine sulfate, $2 \mathrm{mg}$ \\
\hline J9380 & Vincristine sulfate, $5 \mathrm{mg}$ \\
\hline J9390 & Injection, vinorelbine tartrate, $10 \mathrm{mg}$ \\
\hline J9600 & Injection, porfimer sodium, 75 mg \\
\hline J9999 & Not otherwise classified, antineoplastic drugs \\
\hline
\end{tabular}


eAppendix 2: Established Sequential Adjuvant Chemotherapy Regimens for Breast Cancer

\begin{tabular}{|l|l|l|}
\hline Phase 1 & Phase 2 & Phase $\mathbf{3}$ \\
\hline Doxorubicin/cyclophosphamide & Docetaxel & \\
\hline Doxorubicin/cyclophosphamide & $\begin{array}{l}\text { Docetaxel + trastuzumab followed by } \\
\text { Trastuzumab }\end{array}$ & \\
\hline Doxorubicin/cyclophosphamide & Paclitaxel followed by trastuzumab & \\
\hline Doxorubicin/cyclophosphamide & Paclitaxel & \\
\hline Docetaxel + trastuzumab & Fluorouracil/epirubicin/cyclophosphamide & \\
\hline Doxorubicin/cyclophosphamide & Paclitaxel & Cyclophosphamide \\
\hline Doxorubicin & Paclitaxel & \\
\hline Fluorouracil/epirubicin/cyclophosphamide & Docetaxel & \\
\hline 21-day cycle of Trastuzumab for 1 year following at least 4 courses of approved adjuvant chemotherapy
\end{tabular}

Data from The NCCN Chemotherapy Order Templates (NCCN Templates). Available at: NCCN.org. Accessed April 29, 2015. To view the most recent and complete version of the NCCN Templates, go to NCCN.org. 


\begin{tabular}{|lll|}
\hline eTable 1: Patient Characteristics & & N (\%) \\
\hline N & & $13,347(100 \%)$ \\
\hline Stage & I & $2,411(18 \%)$ \\
& II & $7,473(56 \%)$ \\
& III & $2,696(20 \%)$ \\
& IV & $767(6 \%)$ \\
Age, y & & \\
& $>65-70$ & $5,864(44 \%)$ \\
& $>70-75$ & $4,043(30 \%)$ \\
& $>75-80$ & $2,429(18 \%)$ \\
& $>80-85$ & $838(6 \%)$ \\
& $>85$ & $173(1 \%)$ \\
\hline Charlson comorbidity index & & \\
& $>0$ & $9,133(76 \%)$ \\
Prior hospitalization/emergency & $>1$ & $2,081(17 \%)$ \\
department admission & & $821(7 \%)$ \\
\hline Patient received $>1$ regimen-line & & $3,138(24 \%)$ \\
\hline
\end{tabular}

anly patients diagnosed at age $\geq 66$ years are included, because 1 year of prediagnosis claims were required to ascertain comorbidity score. 